\title{
Machado de Assis, cronista: o espiritismo kardecista sob a pena da galhofa
}

Fábio da Silva Júnior¹

$\underline{\text { http://lattes.cnpq.br/1033441239031048 }}$

Enviado em: 15/09/2018

Aceito em: 11/03/2019

Resumo: Este artigo busca compreender como a temática espírita aparece em crônicas de Machado de Assis. Mais especificamente, este estudo se volta para as crônicas publicadas nas cinco séries escritas pelo autor, entre os anos de 1883 e 1897, para o jornal carioca, Gazeta de Notícias. Considerando as mudanças sociais pelas quais o Brasil passou entre as décadas de 1860 e 1890, a situação dos espíritas também se modificou, o que resultou dos progressos e retrocessos políticos do país. Acompanhando as mudanças sociais em seu entorno, Machado também tematizou a ascensão espírita, mostrando sempre o seu posicionamento com relação à nova doutrina. Com isso, visando uma melhor compreensão a respeito do assunto, esta pesquisa busca compreender os recursos utilizados pelo autor para realizar suas críticas contra o espiritismo, especialmente, porque fez uso de diferentes estratégias para escrever cada uma das séries. Dessa forma, na medida em que o espiritismo passou por um processo de ascensão na sociedade oitocentista brasileira, Machado tornou a doutrina tema de suas crônicas, transformando o assunto em uma verdadeira forma de fazer troça dos espíritas, ao mesmo tempo em que converteu a temática em uma forma de criticálos.

Palavras-chave: Machado de Assis; Crônicas; Espiritismo; Literatura e Jornalismo.

Abstract: This article aims to comprehend how the spirituality subject appears in the chronicles of Machado de Assis. More specifically, this study turns to chronicles published in the five series written by the author, between 1883 and 1897, for the carioca newspaper, Gazeta de Notícias. Considering the social changes which Brazil passed between 1860s and 1890s, the situation of the spiritists also changed, and the later resulted from political progress and regress of the country. Following the social changes in his return, Machado also deal with the subject of the spiritism ascension, always showing his position in relation to the new doctrine. Thereby, aiming a better comprehension about the subject, this study aims to comprehend the resources used by the author to make his critics against spiritism, especially, because he used different strategies to write each series. This way, as long as the spiritism passed to the process of ascension, in the Brazilian eighties society, Machado made the doctrine a subject of his chronicles, and he transformed the subject in a truly way to make fun of spiritists, in the same way that the subject became a way to criticized them.

Key-words: Machado de Assis; Chronicles; Spiritism; Literature and Journalism.

(...) Os espiritas que me lerem hão de rir-se de mim, porque é balda certa de todo maniaco lastimar a ignorância dos outros. (...) (ASSIS, 2015, p. 819)

A estréia de Machado de Assis frente às colunas semanais coincidiu com a ascensão da

\footnotetext{
${ }_{1}^{1}$ Mestrando no Programa de Pós-Graduação em Letras, na Universidade Federal de São Paulo (Unifesp), Campus Guarulhos. Bacharel e licenciado em Letras Português / Inglês pela Universidade Federal de São Paulo, Campus Guarulhos. Email: fabio.fsj2@gmail.com
} 
doutrina espírita, no Brasil. O seu ofício de cronista iniciou-se no jornal carioca Diário do Rio de Janeiro, ainda na década de 1860. Foi justamente nesse mesmo período que chegou às terras brasileiras a doutrina codificada na França, em 1857, por Allan-Kardec, mais especificamente, em Le Livre des Esprits, obra traduzida para o português somente em 1875.

Nos anos iniciais do espiritismo kardecista no país, a nova doutrina despertou o interesse, principalmente, dos intelectuais e dos ditos homens das Letras. No entanto, Machado, desde sua primeira menção à doutrina, ainda em 1865, já demonstrava uma postura crítica frente à ascensão espírita. Isso só se intensificou ao longo do tempo, sobretudo, em decorrência da popularização dos princípios doutrinários, o que se deu, sobretudo, por meio da publicação de obras e de suas traduções para a língua portuguesa, como é o caso do já mencionado $\mathbf{O}$ livro dos Espíritos, publicado pela livraria de Baptiste-Louis Garnier, um dos mais importantes livreiros do século XIX, no Brasil.

De acordo com Ubiratan Machado, em Os Intelectuais e o espiritismo: de Castro Alves a Machado de Assis (1996), a doutrina espírita passou pelo que ele chama de sincretismo religioso, isso em decorrência da mistura de diferentes costumes e crenças religiosas, como, por exemplo, as práticas advindas do catolicismo popular, das seitas de origem afrobrasileiras e das crenças religiosas de origem negra. Isso fez com que a doutrina kardecista ganhasse ares locais, o que fez com que se diferenciasse da doutrina codificada na França, originalmente.

Contudo, além do trabalho de Ubiratan Machado, no que diz respeito à relação entre Machado de Assis e o espiritismo, é escassa a produção de trabalhos voltados às crônicas machadianas dedicadas à temática espírita. O único trabalho que se volta para essa questão é a dissertação de mestrado da historiadora Elaine Cristina Maldonado, defendida no ano de 2008, e intitulada: Machado de Assis e o Espiritismo: diálogos machadianos com a doutrina de Allan-Kardec (1865-1896). O foco da estudiosa é o trajeto do espiritismo no Rio de Janeiro oitocentista, tendo como ponto de partida as crônicas publicadas por Machado de Assis, nessas quase quatro décadas de atuação nas colunas semanais.

É desse modo que Maldonado (2008) busca entender em que momento se encontrava a doutrina espírita no Brasil, tendo como base as crônicas de Machado. Dessa maneira, a pesquisadora, ao lançar luz sobre aspectos históricos que tiveram impacto sobre a posição que os espíritas ocupavam na sociedade oitocentista brasileira, mais especificamente, a carioca, reconhece não esgotar esse assunto, ainda passível de análise por outros pesquisadores, segundo perspectivas específicas.

Assim, tendo em vista o já conhecido posicionamento crítico de Machado frente à ascensão espírita no país, reconhecemos que, mesmo o autor sendo tão crítico com relação à nova doutrina, o modo como ele realizou os seus ataques se modificou ao longo do tempo. Isto é, além de ter atuado em diferentes jornais, estando, portanto, à frente de séries distintas e fazendo uso de variados pseudônimos, Machado recorreu a diferentes recursos para criticar os seguidores de Allan-Kardec; o que acaba coincidindo, também, com a situação da doutrina espírita naquele momento, no país.

Considerando a rica produção de Machado ao longo de mais de trinta e cinco anos atuando como cronista, este estudo se volta às crônicas publicadas, especificamente, no jornal carioca, Gazeta de Notícias, pois nele se concentra o maior número de crônicas produzidas pelo bruxo do Cosme Velho. São ao todo 478 crônicas escritas em cinco séries diferentes, a saber: "Balas de estalo" (1883-1886); "A + B" (1886); "Gazeta de Holanda" (1886-1888); “Bons dias!” (1888-1889); e “A Semana” (1892-1897). É justamente nesse 
jornal em que se concentra o maior número de crônicas voltadas à questão espírita. Para a realização do trabalho fazemos uso da edição Machado de Assis: obra completa em quatro volumes, volume 4, publicada em 2015, pela editora Nova Aguilar.

Em "Balas de estalo", primeira série de que fez parte no jornal carioca, Machado atuou ao lado de outros cronistas, como Capistrano de Abreu, Demerval da Fonseca e Ferreira de Araújo, um dos donos e fundadores do jornal. Sob o pseudônimo Lélio, o escritor compôs o time de cronistas entre 2 de julho de 1883 e 22 de março de 1886. Em uma de suas primeiras menções ao espiritismo, em crônica publicada na Gazeta, o narrador-cronista, ao tratar de um trabalho divulgado que refutava a teoria de Isaac Newton, reconhece não entender nada sobre astronomia, o que o leva a consultar o espírito do próprio astrônomo, Newton, por meio da doutrina espírita. É o que vemos, mais precisamente, na crônica datada de 25 de novembro de 1884:

\footnotetext{
Sr. Dr. Castro Lopes escreveu um trabalho para provar que a atração não governa os astros, e o sr. conselheiro Ângelo Amaral refutou-o com uma carta inserta, hoje, no País.

Tratando-se de uma teoria de Newton, e não entendendo eu nada de astronomia, parece-me que o melhor de tudo era consultar o próprio Newton, por meio do espiritismo. Acabo de fazêlo; e eis aqui o que me respondeu a alma do grande sábio:

- Estou acabrunhado. Imaginava ter deixado a minha ideia tão solidamente estabelecida, que não admitisse refutações do Castro Lopes, nem precisasse a defesa do Ângelo Amaral; enganeime. Homem morto, é o diabo. Veja o que aconteceu ao Molière, que foi aí tratado, na Câmara, como um saltimbanco. A mim refutam-me: e (o que é pior) defendem-me. Palavra; isto tira toda a vontade de ser gênio...

Fiz ainda outras perguntas; mas o espírito esvaiu-se, e não me respondeu mais. Ficam aí as únicas palavras que ouvi, e das quais parece concluir-se que Newton ainda está com os seus Princípios.

E agora, para que toda esta bala se componha de ciência, passemos a ver a ironia com que se está portando, delicadamente, o Instituto dos Bacharéis em Letras.

(...) (ASSIS, 2015, p. 517, grifo do autor)
}

O narrador faz uma clara troça do espiritismo, dizendo ter recorrido à comunicação com o espírito do físico, matemático e astrônomo, Isaac Newton, falecido em 1727. Além disso, vemos na fala atribuída ao espírito um tom de desapontamento, sobretudo por ele reconhecer que a sua ideia, até então, irrefutável, estava sendo questionada pelo sr. dr. Castro Lopes, ao mesmo tempo que era defendida pelo sr. conselheiro Ângelo Amaral.

Outro ponto que chama a atenção na crônica é a seguinte menção: "Ficam aí as únicas palavras que ouvi, e das quais parece concluir-se que Newton ainda está com os seus Princípios", de modo que podemos questionar se esses "princípios" se referem, tão-somente, aos pensamentos de Newton, ou seja, às suas teorias; ou se se referem ainda à ideia de o astrônomo, mesmo depois de morto, manter o seu juízo perfeito, portanto, o seu discernimento e equilíbrio mental. Essa segunda interpretação nos conduz à ideia da "loucura espírita”, discurso veiculado na imprensa oitocentista brasileira, como forma de atacar os kardecistas, conforme destaca Ubiratan Machado (1996).

O espiritismo também é tema de crônicas escritas nas séries seguintes, nas quais Machado passou a atuar sozinho. Em cada uma delas, ele recorreu a diferentes recursos e estratégias para escrever; em "A + B”, por exemplo, o autor, sob o pseudônimo de João das Regras, fez uso da forma dialógica para escrever suas crônicas. Nessa série, escrita apenas entre setembro e outubro de 1886, Machado menciona uma única vez a doutrina espírita, isso por meio de uma alusão ao codificador do espiritismo, Allan-Kardec.

Já na série seguinte, intitulada "Gazeta de Holanda", outra forma de composição foi 
adota pelo escritor, pois, como destaca Jefferson Cano (2008), Machado vinha pondo em prática um novo projeto estético para o gênero que produzia desde meados da década de 1860. Dessa forma, o escritor monstruoso, para fazermos uso das palavras de Lúcia Granja (2017), abriu mão do texto escrito em prosa, bem como da forma dialógica da série anterior, para fazer uso do texto escrito em verso. Assim, compondo por meio de quadrilhas, e assinando sob o pseudônimo Malvolio, Machado volta a se referir ao kardecismo, em texto publicado em 2 de novembro de 1887:
(...)
José Telha, que no sótão
Sustenta os seus macaquinhos,
Crê que alguns deles se botam
Para a casa dos vizinhos
Mas eu respondo-lhe a cada
Palavra com heroísmo,
Que o que parece pancada,
É simples espiritismo.
(...) (ASSIS, 2015, p. 709, grifo do autor)

Em alguns textos, a ironia é tão sutil que se torna difícil entender ao que exatamente o autor se refere, como é o caso desse texto. No entanto, nas demais estrofes apresentadas, o narrador aprofunda a sua discussão a respeito do espiritismo, principalmente, ao se referir a um encontro entre o filosofo grego, Sócrates, e um hotentote ${ }^{2}$, o que teria se dado, mais especificamente, em outro plano espiritual:

E, voltando à vaca fria,

Sócrates era um sujeito

De grande filosofia

Alta mente, heróico peito.

O hotentote, - conquanto

Lembre uma Vênus famosa

Pelo volumoso encanto,

Mas tão pouco volumosa

(...)

O hotentote, em bestunto,

É pouco mais que um cavalo;

Dê-se-lhe um simples assunto,

Mal poderá penetrá-lo.

Mas, sendo um e outro feitos

Pela mesma mão divina,

Força é que sejam perfeitos,

Di-lo a grande Espiritina.

Daí a necessidade

De andar a gente em charola,

Não de cidade em cidade,

2 Relativo ao indivíduo dos hotentotes, povo nômade africano, do Sul de África. 
Mas de uma bola a outra bola.

(...) (ASSIS, 2015, p. 709-710)

Sócrates e o hotentote são colocados em pé de igualdade pelo narrador, o que se deve ao fato de terem sido criados pela "mesma mão divina". O encontro entre os dois se dá na eternidade, como é destacado nas últimas duas estrofes do texto:

\author{
(...) \\ Ali Sócrates jucundo \\ Receberá o hotentote, \\ E falarão deste mundo, \\ E glosarão este mote: \\ - Para que há de haver juízes \\ Em Berlim, ou noutra parte? \\ Têm aqui iguais narizes \\ O inocente e Malazarte. \\ (ASSIS, 2015, p. 710)
}

Ou seja, independente da posição que tenham ocupado e do que tenham feito "neste mundo", os dois terão o mesmo tratamento no Além. Isso de fato tem coerência quando pensamos nos princípios doutrinários do espiritismo, isto é, de que tivemos uma mesma origem, portanto, de espíritos simples e ignorantes, como mostrado em O Livro dos Espíritos, atingiremos a perfeição, ao longo de nosso processo evolutivo.

Depois de pouco mais de um ano frente à série "Gazeta de Holanda", Machado deu início, em 05 de abril de 1888, à seção intitulada "Bons dias!", e, nela, voltou a escrever em prosa. Diferentemente das colunas anteriores, em que a autoria de seus textos era de conhecimento, senão por todos os leitores, mas, pelo menos, por parte da imprensa, Machado fez uso de seu completo anonimato, conforme destacam o historiador Sidney Chalhoub (2005) e o crítico literário John Gledson (2006a). Assim, os textos eram finalizados não mais com a assinatura de um pseudônimo, mas, com um cordial "boas noites", forma de despistar os leitores sobre a real identidade daquele que estava por trás da "pena da galhofa".

A publicação dessa série coincide com um conjunto de mudanças ${ }^{3}$ sociais e políticas que teriam grande importância na história do Brasil. Com isso, conforme Gledson (1990):

A série de "Bons dias!", como qualquer série de crônicas, é uma mistura do velho e do novo, do permanente e do ocasional. (...) É como se o apenas eficiente cronista de "Balas de estalo" ou da "Gazeta de Holanda" visse que podia alargar as possibilidades do gênero, lançando mão da trivialidade convencional para seus fins. Que ele viu isto, e viu que precisava de certos ajustamentos no meio, indica-nos o próprio título, e o "disfarce" do velho relojoeiro, que adota na primeira crônica. (...) Na verdade, até certo ponto estes ajustamentos simplesmente retornam às características básicas do gênero, o que de certo modo faz ressaltar estas mesmas características. Afinal de contas, a palavra "crônica" contém em si mesma a noção de "cronos", tempo; e que maneira melhor de introduzir esta "conversa com os leitores" que a crônica reputa ser, do que as palavras "bons dias"? (...) (GLEDSON, 1990, p. 25)

O anonimato na publicação da série certamente permitiu a Machado colocar-se de forma mais crítica frente aos acontecimentos que se passavam à sua volta. Não é à toa que

\footnotetext{
${ }^{3}$ É o caso, por exemplo, da assinatura da Lei Áurea, em 13 de maio de 1888; e o fim gradual e inevitável do Império, como destaca John Gledson (1990).
} 
o tom adotado para se referir aos espíritas kardecistas é de uma ironia mais agressiva, como é possível ver em crônica publicada em 29 de agosto de 1889. Ao tratar de um relatório médico acerca de "drogas" achadas em casa de um curandeiro, o narrador compara o curandeirismo ao espiritismo. Assim, enquanto a primeira prática tem de ser punida (com a ressalva de que "foi a célula da medicina"), a segunda prática é assim entendida pelo narrador:

A segunda é que o espiritismo não é menos curanderia que a outra, e é mais grave, porque se o curandeiro deixa os seus clientes estropiados e dispépticos, o espírita deixa-os simplesmente doidos. O espiritismo é uma fábrica de idiotas e alienados, que não pode subsistir. Não há muitos dias deram notícia as nossas folhas de um brasileiro que, fora daqui, em Lisboa, foi recolhido em Richafoles, levado pela mão do espiritismo. (ASSIS, 2015, p. 819)

Não bastasse o tom adotado na crônica para se referir aos seguidores de Allan-Kardec, o texto é finalizado da seguinte forma:

Os espíritas que me lerem hão de rir-se de mim, porque é balda certa de todo maníaco lastimar a ignorância dos outros. Eu, legislador, mandava fechar todas as igrejas dessa religião, pegava dos religionários e fazia-os purgar espiritualmente de todas as suas doutrinas; depois, dava-lhes uma aposentadoria razoável.

Boas noites. (ASSIS, 2015, p. 819)

Além do sarcasmo com que o espiritismo é tratado, principalmente pelo fato de associar os espíritas aos loucos - o que já era realizado pela imprensa oitocentista brasileira, desde meados da década de 1870, como destaca o estudioso Ubiratan Machado (1996) -, também chama a atenção o fato de ser essa a última crônica da série, o que, de certa forma, mostra o desprezo do cronista com relação à nova doutrina e aos seus seguidores.

Depois dessa última publicação, a "pena da galhofa" só voltou a ser usada nas colunas semanais da década de 1890, mais precisamente, em 1892, quando Machado passou a escrever todos os domingos, para a seção "A Semana", publicada na primeira coluna do jornal carioca. Nela, o autor escreveu mais da metade de toda a sua produção para Gazeta de Notícias $^{4}$, atuando entre 24 de abril de 1892 até 28 de fevereiro de 1897. Sob um novo regime governamental, a configuração social já não era mais a mesma. O progresso da República também trouxe retrocessos para algumas frentes, como a imprensa, pois se vivia em constante clima de censura. Como bem destaca Gledson, em seu ensaio "A Semana” 1892-3: Uma introdução aos primeiros dois anos da série” (2006b):

(...) Nenhum leitor contemporâneo deixaria de perceber que a referência aos jornais não é abstrata, mas concreta - a censura era tão severa que, na tentativa desesperada de preencher as páginas dos diários, se usava tudo: triviais faits divers, notícias estrangeiras, notícias velhas, folhetins antigos, tudo que pudesse encher os jornais que já tinham sido reduzidos de tamanho. (...) (GLEDSON, 2006b, p. 232)

Muitas foram as mudanças, tanto no âmbito social, quanto no âmbito legal. Um novo sistema de governo requeria também novas regras. Foi em meio a isso que em outubro de 1890 se promulgou o Código Penal, no qual o capítulo III "Dos Crimes Contra a Saúde Pública"5 apresentava os seguintes artigos: 156, 157 e 158. A criação desses artigos tinha

\footnotetext{
${ }^{4}$ Ao todo, foram escritas 478 crônicas em Gazeta de Notícias, só para “A Semana” foram 248.

BRASIL. Decreto $\mathrm{n}^{\circ} 847$, de 11 de outubro de 1890. Disponível em: 
por finalidade punir as práticas espíritas. Ao se cometer determinadas práticas, o sujeito incorreria contra os artigos decretados, podendo, assim, sofrer sanções que iam desde o pagamento de multa, até mesmo a prisão, como vemos abaixo:

Artigo 156 - Exercer a medicina em qualquer dos seus ramos, a arte dentária ou a farmácia; praticar a homeopatia, a dosimetria, o hipnotismo ou magnetismo animal, sem estar habilitado segundo as leis e regulamentos:

Penas - de prisão celular por um a seis meses e multa de $100 \$$ a $500 \$ 000$.

(...)

Artigo 157 - Praticar o espiritismo, a magia e seus sortilégios, usar de talismãs e cartomancias para despertar sentimentos de ódio ou amor, inculcar cura de moléstias curáveis ou incuráveis, enfim, para fascinar e subjugar a credulidade pública:

Penas - de prisão celular por um a seis meses e multa de $100 \$$ a $500 \$ 000$.

(...)

Artigo 158 - Ministrar ou simplesmente prescrever, como meio curativo para uso interno ou externo e sob qualquer forma preparada, substância de qualquer dos reinos da natureza, fazendo, ou exercendo assim o ofício do denominado curandeiro:

Penas - de prisão celular por um a seis meses e multa de $100 \$$ a $500 \$ 000 .{ }^{6}$

Esse golpe contra os espíritas resultou em aberturas de processos e perseguições. No entanto, a formulação do Código tinha por finalidade a punição de outras práticas que passaram a ser associadas à nova doutrina, tais como o curandeirismo e a medicina homeopática, comuns na segunda metade do século XIX. Esse mesmo Código que punia, era o mesmo que garantia nos artigos 185, 186 e 187 o livre direito ao culto religioso, assim como a Constituição de 1891, em seu artigo $72, \mathbb{S} 3^{\circ}$. Adriana Gomes, em sua dissertação de mestrado intitulada Entre a fé e a política: o espiritismo no Rio de Janeiro (1890-1909), assim aborda a questão:

No artigo 157 a polêmica foi em torno, também, do artigo 72 , mas no $₫ 3^{\circ}$ da Constituição de 1891, que dava a todos os indivíduos e confissões religiosas o poder para exercerem pública e livremente seus cultos. Portanto, o espiritismo não poderia ter sido criminalizado. Entretanto, o Estado não interpretava as confissões religiosas mediúnicas como religiões reconhecidas pelo Estado, dessa forma, elas seriam passíveis de perseguição pela ilegitimidade religiosa. (...) (GOMES, 2013, p. 82)

Vemos, dessa maneira, que os artigos do Código Penal iam em sentido oposto ao que era estipulado pela Constituição Brasileira, e isso servia como brecha para se reverterem processos (GOMES, 2013). Ainda pensando sobre a promulgação desses artigos, vemos que ou o espiritismo não era considerado como uma religião, ou o Código previa a punição, tão-somente, de um grupo muito específico, no caso as pessoas que praticavam aquele espiritismo à brasileira, resultado da mistura religiosa a que Machado (1996) se referiu.

Foi em meio a essas mudanças sociais que Machado de Assis continuou a criticar os espíritas, e em ataques mais diretos contra os seguidores de Kardec. No entanto, nessa nova série, nem a narrativa ficcional ${ }^{8}$, utilizada nas primeiras séries publicadas no jornal,

http://www2.camara.leg.br/legin/fed/decret/1824-1899/decreto-847-11-outubro-1890-503086-publicacaooriginal-1-pe.html. Acesso em: 14 set. 2018.

${ }^{6}$ Foram feitas as devidas adequações lexicais para adequar à atual norma da língua portuguesa.

${ }^{7}$ BRASIL. Constituição dos Estados Unidos do Brasil (1891). Artigo no 72 de 24 de fevereiro de 1891. Dos Cidadãos Brasileiros. Poder Executivo, Rio de Janeiro, RJ, 24 dez. 1891. Seção 2. Disponível em: http://www.planalto.gov.br/ccivil 03/constituicao/constituicao91.htm. Acesso em: 14 set. 2018.

8 Isso não quer dizer que a narrativa ficcional não esteja presente nas crônicas de "A Semana", exemplo disso são as 
tampouco seus pseudônimos ou seu completo anonimato, como em "Bons dias!", foram utilizados como armadura para se proteger de um possível contra-ataque.

Diferentemente das primeiras séries publicadas em Gazeta de Notícias, em que o cronista fazia uso de pseudônimos para assinar suas crônicas, ou do simples "boas noites", em meio ao seu completo anonimato de "Bons dias!", vemos que, em "A Semana", o escritor não fez uso de um pseudônimo, muito menos de uma cordialidade ao leitor para finalizar o seu texto. Embora as crônicas dessa seção não apresentassem nenhuma assinatura em seu fim, a autoria dos textos era de conhecimento do público, senão dos leitores em geral, mas, pelo menos, por parte da imprensa da época. Prova disso é o artigo de autoria de Arthur Azevedo, publicado em janeiro de 1893, na revista literária O Álbum. No texto, cujo assunto central era Machado de Assis, o autor conclui tratando do atual ofício do escritor:

Atualmente escreve Machado de Assis, todos os domingos, na Gazeta de Notícias, nos artigos intitulados $A$ Semana, que n'outro país mais literário que o nosso teriam produzido grande sensação artística. (AZEVEDO, 1893, p. 11, grifos do autor) ${ }^{9}$

Esse trecho, além de demonstrar que a autoria dos textos era de conhecimento, pelo menos por parte do público, também dá uma ideia do reconhecimento da qualidade artística das crônicas machadianas. Como ficou dito, nesse período em que ele atuou em "A Semana" a sociedade brasileira sofria o ônus de viver sob um novo regime governamental, enquanto a imprensa vivia em um constante clima de censura e de repressão. A promulgação do Código Penal e de uma nova Constituição, de igual modo causavam rebuliço no âmbito social, tendo em vista, principalmente, que a perseguição contra as práticas espíritas ocorria em um Estado que garantia a liberdade de culto religioso.

Machado, não alheio a essas incoerências legais, também problematizou isso em suas crônicas, expondo sempre uma visão muito crítica com relação às práticas espíritas. É o que ocorre, por exemplo, em crônica datada de 27 de outubro de 1895, em que o autor abordou um caso que repercutiu muito na época, principalmente na imprensa, como destaca Ubiratan Machado (1996). O texto trata do famoso caso de uma jovem, chamada Inês. Após um ataque nervoso, durante uma sessão espírita, a moça foi recolhida a uma casa vizinha de onde era realizado o encontro, e lá faleceu pouco tempo depois.

Para apresentar esse assunto, o narrador da crônica, de forma descontraída, diz ter estado com alguns amigos em um chá da tarde e, depois de uma conversa sobre "fenômenos obscuros", lembrou-se do caso da moça. Dessa forma, o tema central do texto é introduzido: "Então, lembrei-me do caso daquela Inês, moradora à rua dos Arcos no 18, que achou a morte, assistindo a uma sessão da Associação Espírita, rua do Conde d'Eu. (...)” (ASSIS, 2015, p. 1139). Dando sequência ao assunto, o narrador destaca:

Inês, assistindo à prática do sr. Abalo, que é o presidente da associação, teve um ataque nervoso que, segundo os depoimentos, se transformou em sonambulismo. Transferida pelos fundos da

crônicas publicadas em Páginas recolhidas, em 1899. Nesse livro, o cronista reuniu, além de contos, também uma peça e seis crônicas por ele selecionadas, dentre as quais podemos destacar: "O sermão do diabo", publicado originalmente em 04 de setembro de 1893, e "A cena do cemitério", publicado em 03 de junho 1894. Ambos os textos só receberam título quando passaram a compor o livro, assim como as outras quatro crônicas: "V ae soli", "Salteadores da Tessália", "Canção de piratas" e "Garnier". Esses textos podem ser encontrados em: Machado de Assis: obra completa em quatro volumes, volume 2, da editora Nova Aguilar.

9 Ver: AZEVEDO, Arthur. Machado de Assis. In: O Álbum. Rio de Janeiro, n. 2, p. 09-12, janeiro de 1893. Fonte: Hemeroteca digital da Biblioteca Nacional. 
casa $n^{\circ} 146$ para a casa no 144, ali morreu às 5 horas da manhã. Paulina, que é o médium da associação, depôs que Inês nunca antes assistira a tais sessões, e que já ali chegara, meio adoentada. Outras pessoas foram ouvidas, entre elas o presidente Abalo, que fez declarações interessantes. Insistia em que as práticas ali são meramente evangélicas, e entrou em minudências que reputo escusadas ao meu fim. (ASSIS, 2015, p. 1139)

Como vemos, Machado abordou um caso que de fato aconteceu, mas, diferentemente das séries anteriores, vemos, nessa crônica, a utilização de outros recursos. Alguns desses elementos nos remetem a outro gênero presente nos jornais, no caso, a notícia. Nela, encontramos também informações detalhadas sobre os acontecimentos relatados, pois, como apresenta Nilson Lage, em Estrutura da Notícia (2003): "Não basta ser verdadeiro; é preciso parecer. Daí a aversão a referências imprecisas (...)" (LAGE, 2003, p. 26, grifos do autor).

$\mathrm{Na}$ crônica que mencionamos, mais especificamente, além da referência ao caso ocorrido, temos, ainda, informações quanto ao lugar e à hora em que tudo ocorreu, o que é uma forma de apresentar dados não conhecidos ou esquecidos pelo leitor. Esses elementos enriquecem o texto, dando a ele um aspecto jornalístico. À vista disso, o narrador dá sequência à sua narração, apresentando, criticamente, o desdobramento do caso:

O meu fim é mais alto. Não quero saber se Inês faleceu do ataque, nem se este foi produzido pela prática evangélica do presidente, que aliás declarou na ocasião ser coisa desacertada levar àquele lugar pessoas sujeitas a tais crises. Também não quero saber se todas as moléstias, como diz o médium, são curáveis com um pouco d'água e um padre-nosso (...) ou se basta este mesmo padre-nosso e a palavra do presidente; ambas as afirmações se combinam, se atendermos a que a melhor água do mundo é a palavra da verdade. (...)

A questão substancial, e posso dizer única, é a liberdade. O presidente Abalo e o médium Paulina confessaram já ter sido processados, com outros membros da associação, por praticarem o espiritismo. O primeiro acrescentou que, se bem conheça o artigo 157 do código penal, exerce o espiritismo de acordo com a disposição do artigo 72 da Constituição. (ASSIS, 2015, p. 11391140)

Nesse ponto, tomamos conhecimento que, além de os acusados já terem sofrido processo em decorrência da mesma prática, fazem uso das contradições legais para se protegerem. É justamente o fato de os médiuns estarem em liberdade, mesmo depois de terem sofrido um primeiro processo, que leva o narrador a criticar, não propriamente a prática espírita, mas os resultados que dela podem decorrer, como é o caso do falecimento da moça. Com isso, o narrador dá sequência à apresentação do caso:

Os entendidos terão resposta fácil; eu, simples leigo, não acho nenhuma. Deixo-me estar entre o código e a Constituição, pego de um artigo, pego de outro, leio, releio, tresleio. Realmente, a Constituição, mãe do código, acaba com a religião do Estado, e não lhe importa que cada um tenha a que quiser. Desde que a porta fica assim aberta a todos, em que me hei de fundar para meter na cadeia o espiritismo? Responder-me-ás que é uma burla; mas onde está o critério para distinguir entre o Evangelho lido do presidente Abalo, e o lido pelo vigário da minha freguesia? Evangelho por Evangelho, o do meu vigário é mais velho, mas uma religião não é obrigada a ter cabelos brancos. Há religiões moças e robustas. Curar com água? Mas o já citado padre Kneipp não faz outra coisa, e o código, se ele cá vier, deixa-lo-á curar em paz. Quando o médium Paulina declara que recebe os espíritos, e transmite os seus pensamentos aos membros da associação, eu se fosse código, diria ao médium Paulina: Uma vez que a Constituição te dá o direito de receber os espíritos e os corpos, à escolha, fico sem razão para autuar-te, como mereces, minha finória; mas não te exponhas a tirar algum relógio aos associados, que isso é comigo. (ASSIS, 2015, p. 1140) 
Dessa forma, o narrador faz-se de desentendido em meio a essa contradição, mostrando-se um leigo quanto ao assunto: "Os entendidos terão resposta fácil; eu, simples leigo, não acho nenhuma". Tendo em vista que a Constituição garantia a liberdade de culto religioso - o que, para ele, é demonstrável pelo fato de não se punirem as práticas do padre Kneipp -, o narrador se questiona em que iria se basear para "meter na cadeia o espiritismo". É assim que ele, na condição de código, diria o seguinte, ao médium: “(...) não te exponhas a tirar algum relógio aos associados, que isso é comigo". A ameaça do narrador se dá pelo fato de a Constituição garantir a liberdade religiosa, mas não proteger aqueles que furtavam objetos. Isso está de acordo com o parágrafo seguinte do texto, que apresentamos abaixo:

O espiritismo é uma religião, não sei se falsa ou verdadeira; ele diz que verdadeira e única. Presunção e água benta cada um toma a que quer, segundo o adágio. Hoje tudo vai por adágios. Verdadeiros ou não, escrevem-se e publicam-se inúmeros livros, folhetos, revistas e jornais espíritas. Aqui na cidade há uma folha espírita ou duas. Não se gasta tanto papel, em tantas línguas, senão crendo que a palavra que se está escrevendo é a própria verdade. Admito que haja alguns charlatães; mas o charlatanismo, bem considerado, que outra coisa é senão uma bela e forte religião, com os seus sacerdotes, o seu rito, os seus princípios e os seus crédulos, que somos tu e eu? (ASSIS, 2015, p. 1140)

Vemos claramente que o espiritismo é colocado como charlatanismo, o que está de acordo com a passagem apresentada mais acima. Isto é, fica expressa a ideia de que o espiritismo não é uma doutrina verdadeira, ou melhor, ainda que se coloque como verdadeira, sempre estará iludindo e enganando os seus seguidores.

Apresentamos, quase que integralmente o texto, porque consideramos o seu teor um exemplo claro do modo como o cronista passou a abordar a temática espírita em suas crônicas. Com isso, os argumentos utilizados para criticar os espíritas kardecistas se basearam, justamente, nos fatos noticiados pela imprensa, não mais sendo abordado por meio da produção ficcional, como expusemos aqui.

Isso tornou essa narrativa muito mais próxima de gêneros jornalísticos como a notícia, o que a distancia, em certa medida, das publicações das séries anteriores, em que a narrativa da crônica se aproximava mais de gêneros literários, pelo fato de recorrer à ficcionalidade, como o conto. Além disso, o cronista fez uso da contradição que havia entre o que fora promulgado pelo Código Penal, e o que foi estabelecido pela Constituição como forma de evidenciar que muitas pessoas recorriam a isso para de se livrarem de processos criminais.

Assim, mais do que um simples ato de criticar por criticar, Machado parece reconhecer na doutrina espírita mais uma teoria doutrinária a angariar simpatizantes; talvez, muito semelhante àquela criada pelo personagem filósofo, Quincas Borba, e denominada "Humanitismo". Na concepção do crítico literário, Roberto Schwartz, em Um mestre na periferia do capitalismo: Machado de Assis (2000), esse pensamento, criado pela personagem, seria uma crítica à floração oitocentista de "ismos", como, por exemplo, o positivismo, o darwinismo, e outras doutrinas em voga na segunda metade do século XIX.

Fato é que a temática espírita se faz presente não somente nas crônicas machadianas, mas também em contos, como em "Uma visita de Alcibíades" e "A segunda vida", publicados, respectivamente, em 1882 e 1884 . O mesmo ocorre em romances, como é o caso de Quincas Borba (última versão publicada em 1891), Esaú e Jacó (1904) além de Memórias Póstumas de Brás Cubas, romance narrado e protagonizado pelo defunto-autor, 
Brás Cubas e publicado em 1881.

\section{Referências}

ASSIS, Machado. Bons dias! Introdução e Notas de John Gledson. São Paulo: Hucitec; Editora da UNICAMP, 1990.

. Machado de Assis: obra completa em quatro volumes, volume 4. Org. Aluizio Leite Neto, Ana Lima Cecilio, Heloisa Jahn. - 3a ed. São Paulo: Editora Nova Aguilar, 2015. CANO, Jefferson et al. Narradores do ocaso da monarquia (Machado de Assis, cronista). In: Revista Brasileira. Academia Brasileira de Letras, n. 55, 2008, p. 289-316.

CHALHOUB, Sidney. A arte de alinhavar histórias: a serie "A + B" de Machado de Assis. In: __ _ NEVES, Margarida de Souza; PEREIRA, Leonardo Affonso de Miranda. (Orgs.).Histórias em cousas miúdas: capítulos de história social da crônica no Brasil. Campinas, SP: Editora da UNICAMP, 2005. p. 67-86.

GLEDSON, John. Introdução. Trad. Lourdes Dias. In: ASSIS, Machado. Bons dias! São Paulo: Hucitec; Editora da UNICAMP, 1990. p. 11-34.

. "Bons dias!". Trad. John Gledson, Walter Costa, Lúcia Granja e Cristina Carletti.

In: _. Por um novo Machado de Assis: ensaios. São Paulo: Companhia das Letras, 2006a. p. 134-187.

. "A Semana" 1892-3: Uma introdução aos primeiros dois anos da série. Trad. Maria

Teresa David. In: Por um novo Machado de Assis: ensaios. São Paulo: Companhia das Letras, 2006b. p. 207-235.

GOMES, Adriana. Entre a fé e a polícia: o espiritismo no Rio de Janeiro (1890-1909). 2013. 153 f. Dissertação (Mestrado em História Política) - Universidade do Estado do Rio de Janeiro - RJ.

GRANJA, Lúcia. Um editor no espaço público: Baptiste-Louis Garnier e a consolidação da coleção em Literatura Brasileira. Estudos Brasileiros. São Paulo, 45 (3): p. 1205-1216, 2016.

- Machado de Assis, esse escritor monstruoso (entre aberrações e espetáculos). Olho d'água. São José do Rio Preto, 9(1): p. 1-230, Jan.-Jun./2017.

KARDEC, Allan. O livro dos espíritos. Federação Espírita Brasileira. Departamento Editorial e Gráfico. Rio de Janeiro, 2004.

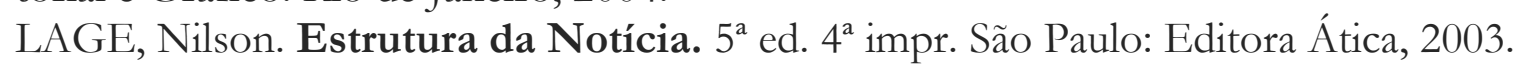

MACHADO, Ubiratan Paulo. Os Intelectuais e o espiritismo: de Castro Alves a Machado de Assis. Niterói: Publicação Lachâtre, 1996.

MALDONADO, Elaine Cristina. Machado de Assis e o Espiritismo: diálogos machadianos com a doutrina de Allan Kardec (1865-1896). 2008. 95 f. Dissertação (Mestrado em História Social) - Faculdade de Ciências e Letras de Assis. Universidade Estadual Paulista. SCHWARZ, Roberto. Um mestre na periferia do capitalismo: Machado de Assis. São Paulo: Duas Cidades; Ed. 34, 2000.

VALLE, Daniel Simões do. Intelectuais, espíritas e abolição da escravidão: os projetos de reforma na imprensa espírita (1867-1888). 2010. 193 f. Dissertação (Mestrado em História) - Universidade Federal Fluminense. Instituto de Ciências Humanas e Filosofia. 